\title{
Build and operate logistic chains - An approach to synchronise distributed production activities
}

T. Kuhlmann*, R. Lamping*, and C. Massow**

* BIBA - Bremen Institute of Industrial Technology and Applied Work Science, P.O. Box 3305 60, 28335 Bremen, Germany

Phone: (49) 421218 5540, Fax: (49) 4212185510

E-mail:lam@biba.uni-bremen.de

** UNIQUE GmbH, Richard-Dehmel-Straße 56, 28211

Bremen, Germany, Phone: (49) 421237604 ,

Fax: (49) 421237605 , E-mail: massow.unique@bigfoot.com

\begin{abstract}
This paper is to discuss the demands of a system to support the configuration and organisation of an Extended Enterprise. Therefor, after a short description of the special requirements of the project management in distributed One-of-a-Kind manufacturing, the paper will introduce the features of the Graphical Interactive Rough Planning System GIGROS with focus on the multi-enterprise approach.
\end{abstract}

Keywords

Multi Agent Systems, Decentralized Production, One-of-a-Kind Production

\section{INTRODUCTION}

One of the special features of customer order processing in the production of complex one-of-a-kind products is, beside the individuality of the product and the required production processes, the deep involvement of different companies. Due 
to these characteristics, a separate, all-embracing project management concept for OKP is needed. This concept must cover all phases of the project live cycle from definition to dissolvement. In the definition phase support to create the project structure with respect to the product structure is demanded as well as for make or buy decisions and the selection of project partner. In the operation phase the harmonisation of distributed production and its activities with respect to time and content is given priority. Customer orders are handled as projects and the simultaneous production processes, their activities and the resource requirements are harmonised with multi-projects in mind. During the dissolvement the project experience and the knowledge gained have to be stored and processed towards an input for decisions in the future.

Based on this, a project co-ordination and control concept was developed. The concept consists of a decentralised independent planning and control level for autonomous production areas and a centralised planning and co-ordination level. This integrated concept enables the devolution of decision making to the lowest possible level of operational responsibility. Therefore, the planning activities of autonomous production areas are supported by decentralised shop floor monitoring and control (SMC) systems.

Table 1 Dimensions and parameter of inter-organisational co-operation

\begin{tabular}{|l|c|c|c|c|c|}
\hline \multicolumn{1}{|c|}{ Dimension } & \multicolumn{4}{|c|}{ Parameter } \\
\hline $\begin{array}{l}\text { Enterprise } \\
\text { functions }\end{array}$ & $\begin{array}{l}\text { Research and } \\
\text { Development }\end{array}$ & Procurement & Production & Sales & Finance \\
\hline $\begin{array}{l}\text { Position in } \\
\text { Value Chain }\end{array}$ & vertical & horizontal & \multicolumn{2}{|c|}{ diagonal } \\
\hline $\begin{array}{l}\text { Direction of } \\
\text { expansion }\end{array}$ & vertical & horizontal & \multicolumn{2}{|c|}{ diagonal } \\
\hline $\begin{array}{l}\text { Effect on } \\
\text { competition }\end{array}$ & promoting & neutral & \multicolumn{2}{|c|}{ limiting } \\
\hline $\begin{array}{l}\text { Type of } \\
\text { entanglement }\end{array}$ & arrangement & reciprocal deliveries & pooling \\
\hline Interdependence & none & minor & moderate & heavy \\
\hline Orientation & local & regional & national & international \\
\hline Duration & unique & limited in time & unlimited in time \\
\hline
\end{tabular}




\section{THE EXTENDED ENTERPRISE}

The Extended Enterprise is according to Browne and Jagdev "the formation of closer co-ordination in the design, development, costing and the co-ordination of respective manufacturing schedules of co-operating independent manufacturing enterprises" (Browne 1996). The initial attempt is to gain competitive advantage from close inter-organisational co-operation within the supplier chain and the distribution chain.

The term "inter-organisational co-operation" deal with a multi-dimensional Phenomena. Co-operation can be described concerning parameters motivation, contents, orientation, duration position in the value chain and so forth. An sample of dimensions and their parameter to classify types of co-operation is given in table 1. The selection of criteria has been done to define the co-operation in the form of an Extended Enterprise. The marked fields in table 1 characterise the interorganisational co-operation of independent manufacturers in a typical Extended Enterprise.

\subsection{Trend of changes in manufacturing}

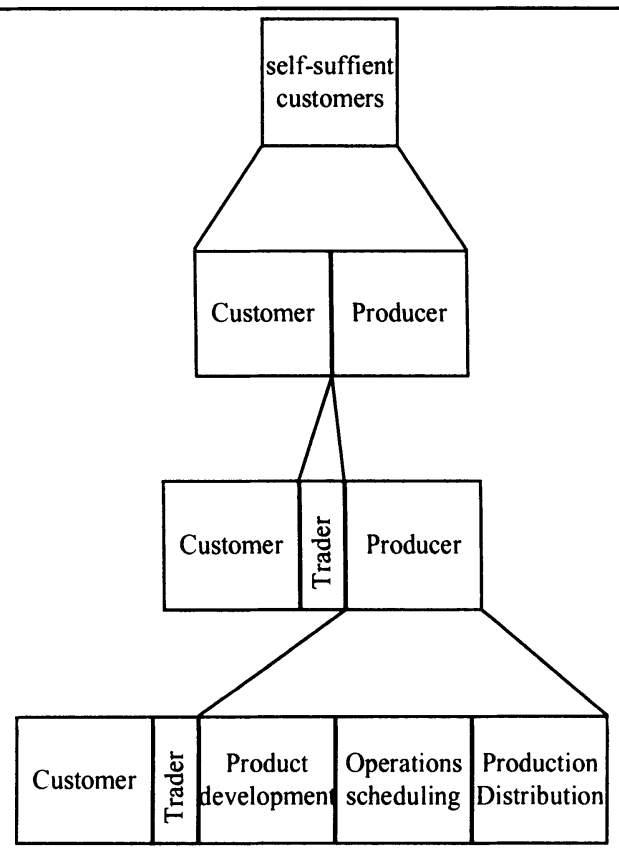

Figure 1

Evolution of roles in the manufacturing environment. 
The structure of the manufacturing environment is changing steadily. If one looks at the way how a demand gets satisfied, the amount of involved parties increased over time. Figure 1 illustrates this trend from demand and his satisfaction in one hand (self-sufficiency) to diversified manufacturing as we know it today.

The trend is characterised by an increasing separation of product (service) specification and production. The Extended Enterprise (and similar approaches) marks another shift in the traditional thinking about the structure and organisation of industrial manufacturing.

Company borders vanish. Customers dictate production. Resources and abilities are available world-wide. Hence the production as such steps back and all indirect manufacturing activities become more important.

\subsection{Roles in industrial manufacturing}

If the trend of changes as described above is stabile, the future may see the roles in industrial manufacturing as depicted in Figure 2. There might be a re-approach of producers to customers - respectively vice versa - (increasing customer influence). A new type of specialists to understand and specify the customers demand (let us call them Product Architects) might appear. Experts (Enterprise Architects) will manage manufacturing resources to satisfy the specified demand organising world-wide distributed for each individual case. The transitions between the different roles are fluid.

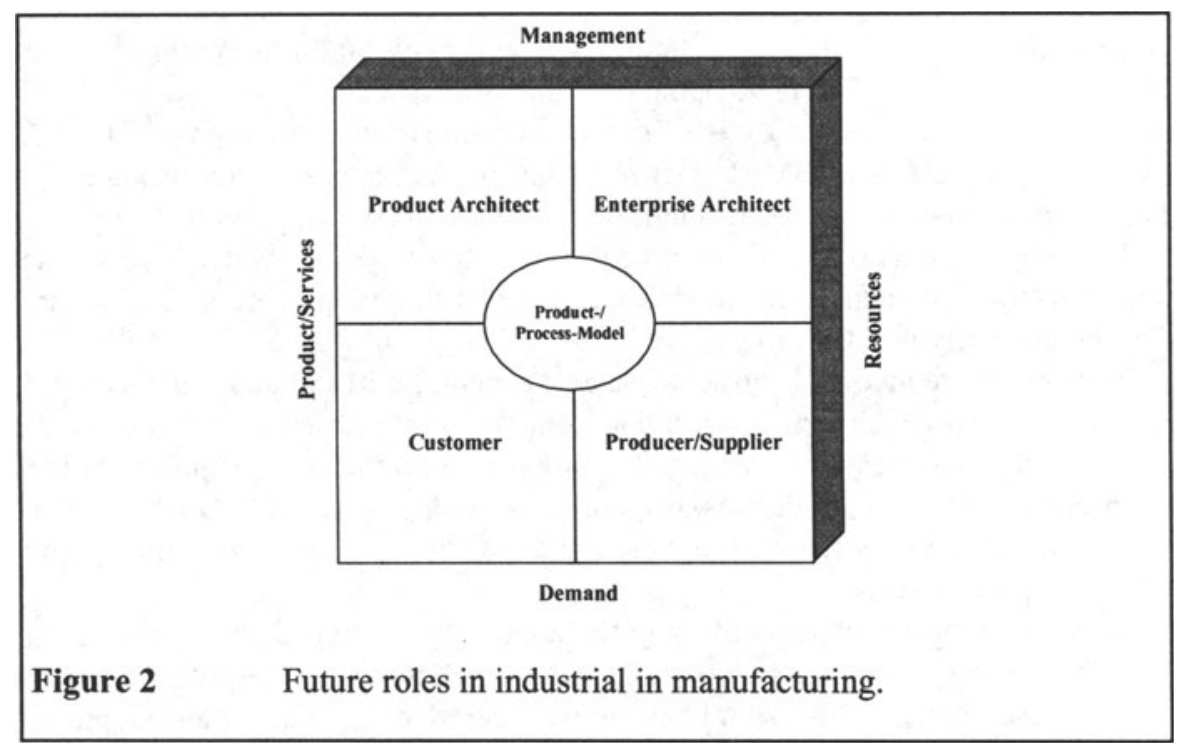

The main task of the Enterprise Architect in this scenario is to configure the Extended Enterprise. This includes 
- determination of activities according to the specified demand;

- selection of technologies;

- selection of partner;

- distribution of tasks;

- scheduling of activities;

- resource-, risk- and cost-management;

- organisation of technical infrastructure (CT and IT).

\section{SUPPORT OF THE ENTERPRISE ARCHITECT}

What kind of tool could support Enterprise Architects by configuring the Extended Enterprise?

Looking at the definition for the Extended Enterprise given above and at the Architects tasks in this context reminds heavily of project management. A project is mostly defined as a non-routine, none-repetitive, one-off undertaking, normally with discrete time, financial and technical performance goals. Project Management is the planning, scheduling, directing, and controlling of company resources for an ad hoc effort which has been established for the completion of specific goals and objectives.

These similarities lead to the idea of using project management methods and tools to support people by building and running Extended Enterprises.

The Bremen Institute of Industrial Technology and Applied Work Science at the University of Bremen (BIBA) has developed a system for the production coordination in the shipbuilding industry to support the decentralisation of production planning. The development of the system was subject in the ESPRIT project MUSYK sponsored by the European Commission and the project ITiS-E, sponsored by the former BMFT (German Ministry for Research and Technology). This project management application, so called GIGROS, supports the long- and middle-term production-planning of complex one-of-a-kind products. GIGROS was enhanced by additional modules dealing with the project definition and dissolvement phase of the project live-cycle.

Considering the involved software-systems concurrent manufacturing demands a movement from centralised towards increasingly decentralised models of control and action. Our goal has to be to support decentralised planning entities (respectively different enterprises) each of them equipped with a GIGROS-system. A central challenge is the co-ordination and synchronisation of activities within those complex systems.

To improve the system according to the approaches sketched above, it is being redesigned towards a project management tool for Extended Enterprises. Today it provides solutions for the simultaneous, co-operative and decentralised project definition, scheduling and resource planning. 


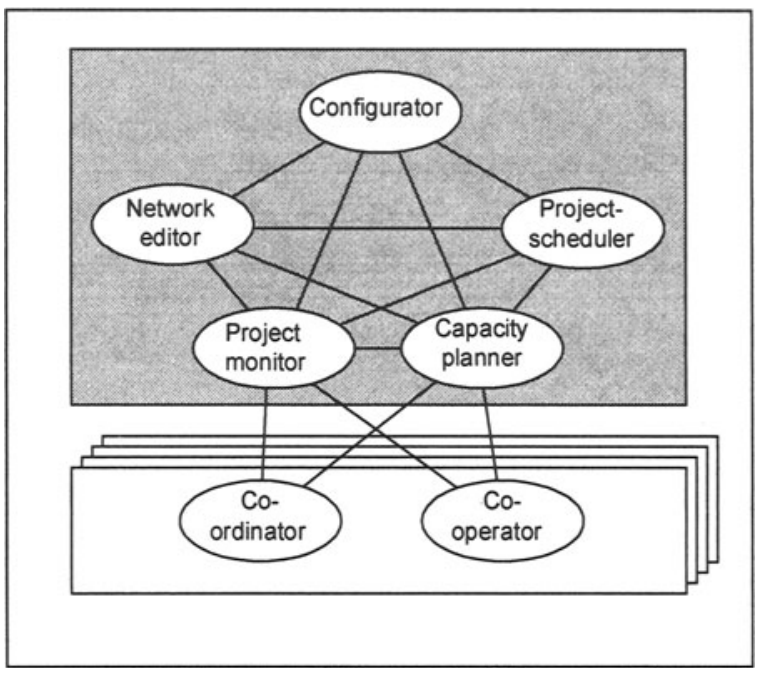

Figure 3 Elements of the enhanced GIGROS.

\subsection{Configurator}

Aim of the configuration module is to support the first phase of a project, in which the project is build up. In addition it helps to lay the foundation for the operation of the project by the pre-description of communication processes (functions see Figure 4). A product modell imported from a CAD-System in the form of a STEP Physical File builds the input for the project definition. To perform the partner selection we use a neural network approach.

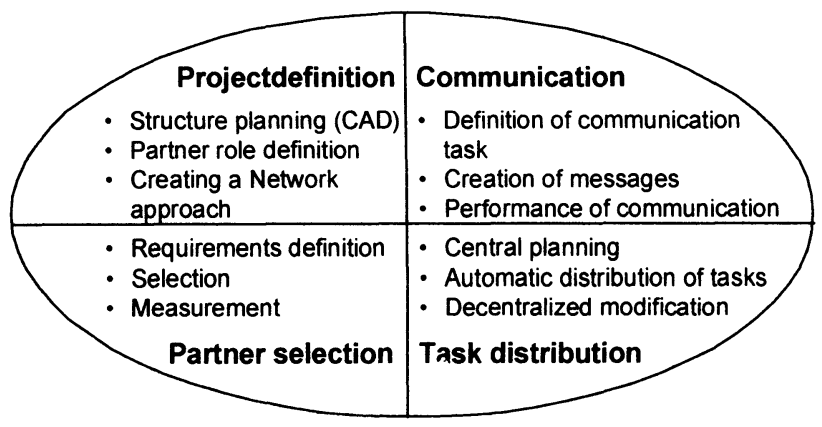

Figure 4 Tasks of the Configurator.

The task definition happens on the base of a project structure plan. Principally there is the free choice concerning the criteria for the structure. For the purposes of an Enterprise Architect an object (product) orientation should be preferred. The 
Configurator offers to import a product description in STEP format from a CAD application to use it as a start for the task structuring process. The vertical product/project structure will be converted into an horizontal activity model of the MPM network type. The Network Editor gives later on the opportunity to expand this first network approach.

Three steps has to be made for the partner selection.

1. Capturing of experience concerning partners abilities and behaviour gained during finished projects.

2. Definition of requirements to partners concerning a new project and partner roles in it.

3. Selection of appropriate partner using a trained neuronal network. Therefor this element of the Configurator consists of a database to store the relevant experience and requirements data, and an user interface.

The communication element of the Configurator allows the definition of communication tasks on the base of the MPM network. The communication element is represented by a set of additional attributes of the relationship of the activities. The respective communication processes are triggered by status changes of activities or time stamps etc.

The distribution of the tasks towards the project partners is supported by STEP conform interfaces to export respectively import networks/sub-networks and partial networks to (and from) the partners. The performance of the defined communication tasks is also the aim of this element.

\subsection{Network Editor}

Incomplete information about product and processes at the beginning of the order processing is a characteristic of OKP manufacturing. Depending on the availability of information activities will be further detailed in course of time through subordinate nets of activities. But in contrast to other approaches activities on higher levels are not substituted by the nets of activities on lower levels. Thus it is possible to draw relations between those sub-nets in order to support management and modelling of simultaneous or overlapping production activities. Order processing in the OKP industry especially, requires project models with approximately a hundred production activities and their corresponding technological and chronological inter-dependencies. Therefor the Network Editor allows the representation and the definition of a selected project in an activityoriented network. In order to guarantee a clearly arranged representation (essentially defined by the number of crossings of interdependencies) an heuristic for the arrangement of activities has been integrated through which the number of crossings has been minimised. (Kuhlmann et al 1994) 


\subsection{Deterministic Scheduler}

Managing complex projects a major task is to determine the start- and due-dates for activities. This is supported by our hierarchical network scheduling approach. Activities on higher levels provide time-frames for the sub-nets on a lower level. Scheduling of sub-nets is possible only within this given frame. Thus a support of partially autonomous and decentralised production areas is provided.

The deterministic scheduling is a prerequisite to the consideration of a project in the decision supporting modules. In order to achieve an event-driven production co-ordination, the function "scheduling" can be performed both project oriented and under consideration of the feedback data. If there are project inconsistencies i.e. unallowed loops or time limits the function "fault analysis" undertakes the search process. (Kuhlmann et al 1994)

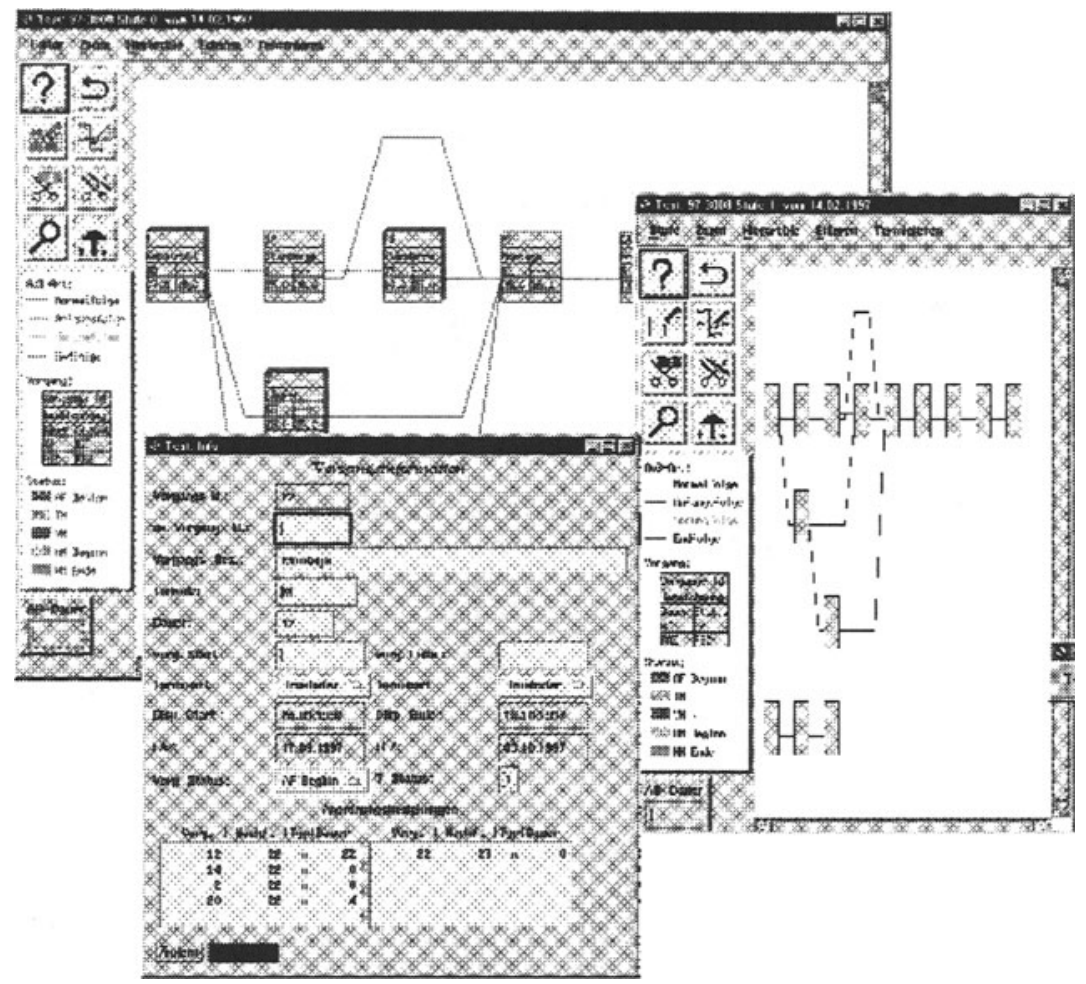

Figure $5 \quad$ Network Editor. 


\subsection{Capacity Planner}

Capacity demand as well as available capacities are more or less subject to change in course of time. The task of the resource planning is to align capacity demand and available resources. GIGROS supports to determine the availability of resources as well as the estimation of demands and its temporally distribution. This module is the main module for the required multi-project planning and supports the experts in a variant manner with regard to the decision required for capacity smoothing and balancing. The analysis of planning activities and the intensive discussion with the planning experts shows that an automatic capacity levelling and smoothing module won't be appropriate. The set of co-ordination module must therefore be extended with respect to an interactive scheduling and capacity module. The decision process is performed for a definable time frame and considers only scheduled projects belonging to selected project classes. The graphical representation of the necessary information and the functional support takes place essentially within the following windows which are fully integrated.

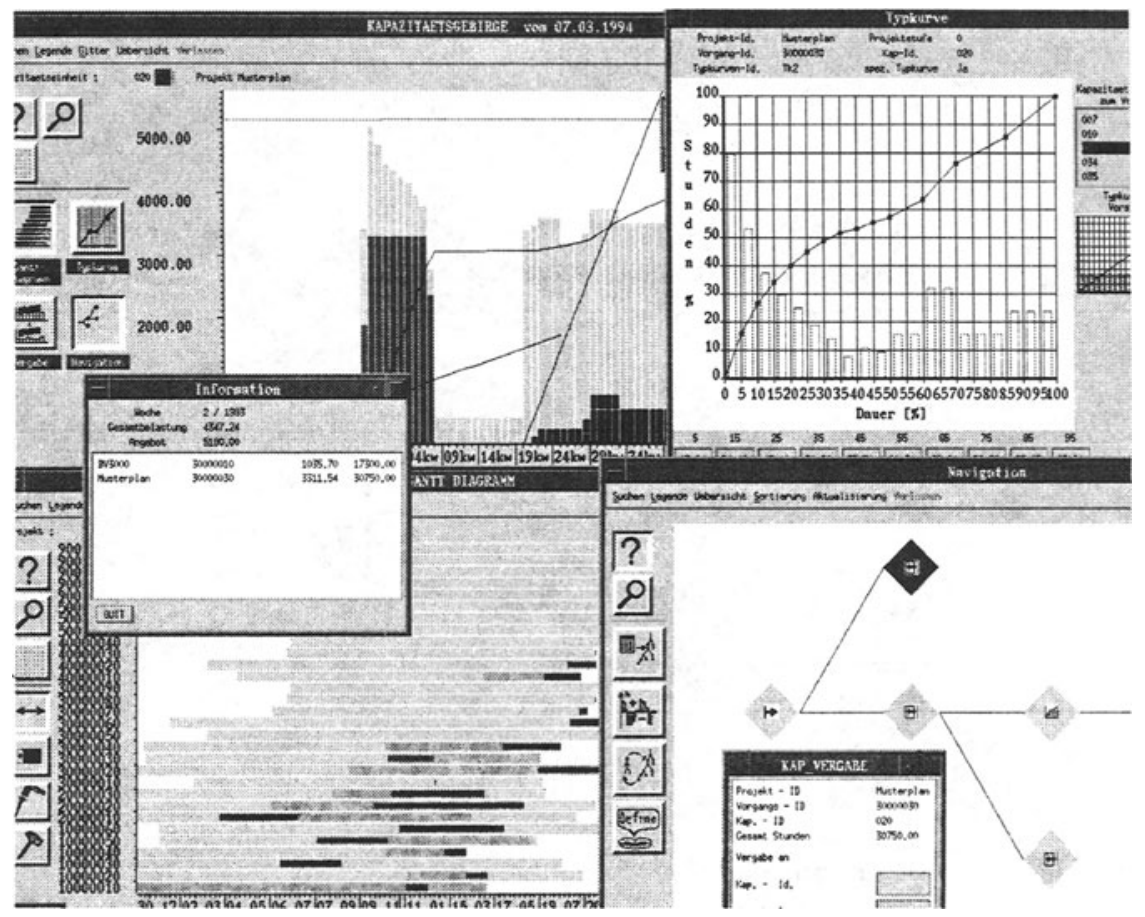

Figure 6

Capacity Planer. (Kuhlmann et al 1994). 


\subsection{Co-ordinator}

The analysis of the process of production planning and control of yards has demonstrated the gap between the centralised multi-project planning and the control of autonomous production areas. A first approach to integrate the different planning areas and to harmonise the planning decisions under consideration and protection of the autonomy is the implementation of a Centralised Co-ordination Module. The harmonisation approach of this module is based on the concept of vertical harmonisation by intervention. A main requirement for the module is "the concentration on essential aspects" which means that it is insufficient to plan each job of a production order separately at the co-ordination level. Consequently, the centralised co-ordination plans and controls so-called "blocks" e.g. jobs of an order belonging to a specific production area are aggregated.

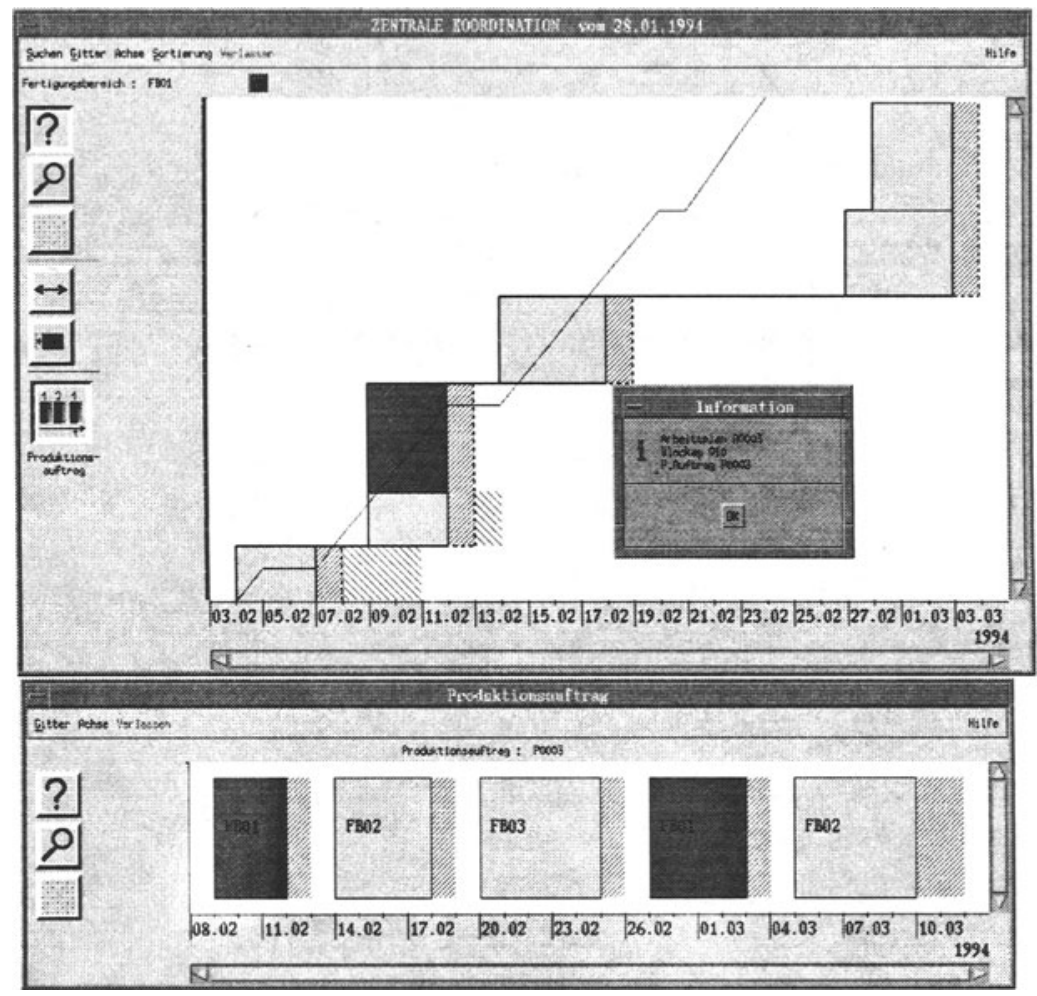

Figure 7 Coordinator. 


\subsection{Co-operator}

In situations in which the production departments cannot guarantee their due dates, i.e. in the case of plan deviations or unrealistic dates, a dialogue between the involved planning experts of the different planning units is required. At present the dialogue is achieved by co-ordination meetings performed several times a week. The aim of this module is not only to support such a co-operative harmonisation strategy, but also to reduce the expenditure of such co-ordination meetings by means of a CSCW-system. In order to minimise the expenditure with regard to time, the co-operative co-ordination module has to support synchronously distributed interaction of the planning experts. Synchronously means that the interactions of the experts occur at the same time. The interactions are distributed as the participants of a meeting do not come together, but are located at different places. This requirement demands an audio communication between the participants possible via existing hardware in the planning units.

\subsection{Integration}

Whether it is a single enterprise or an extended one, there is always the need of communication between rough planning (project management) system on the one side, other systems of the same kind, Material Requirement Planning System(s) and Production Activity Control System(s) on the other side. GIGROS can be seen as one element of such an integrated information system architecture. It provides bi-directional interfaces with:

- The production planning and control system 4PM (VSS, Germany);

- The product-oriented production control system PROOFER (UNIQUE,);

- The graphical spatial resource management tool SPARE (UNIQUE, Germany);

- Other GIGROS systems via Step Physical File (SPF).
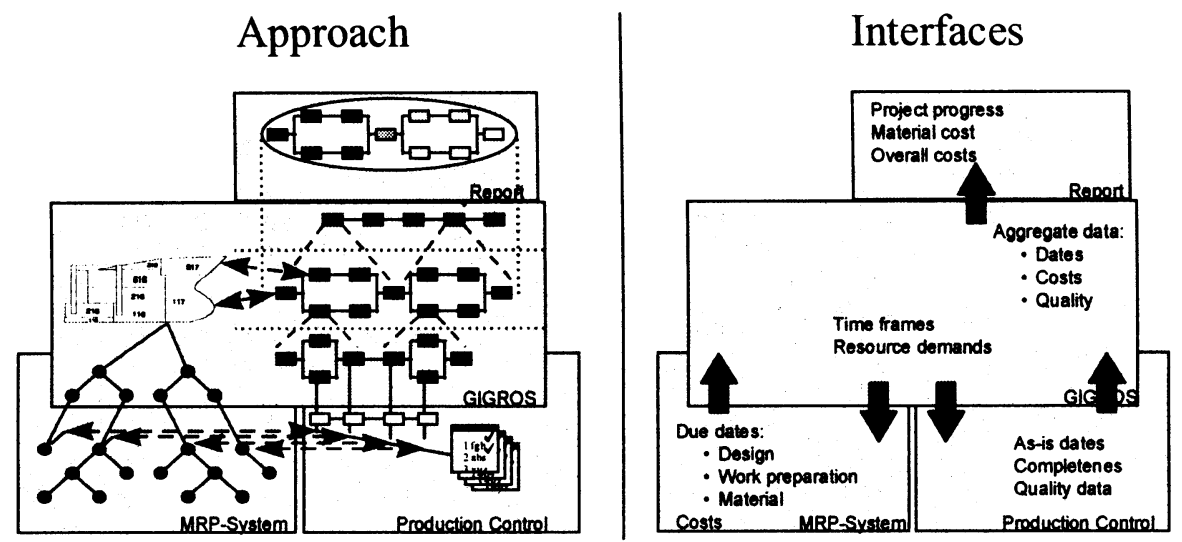

Figure 8 Overall system architecture. 


\section{SUMMARY}

In our paper we described the characteristics of future manufacturing environments and outlined a concept for the support of production co-ordination of decentralised, autonomous productive units. Additionally we introduced a set of software modules to support this concept with our co-ordination system GIGROS.

The concept behind this system could serve as an approach to co-ordinate activities within an extended enterprise. In integration with local systems GIGROS could provide the extended schedule and the time frames for the activities of the autonomous partners. Additionally GIGROS is able to monitor and visualise the progress of work in the extended context.

Though we fell that GIGROS is a suitable tool to synchronise distributed production activities already, there is ongoing work for system functionality enhancements. For example:

- cost management features;

- management of disturbances (e.g. part tracing, pin board);

- product monitoring functionality's.

\section{REFERENCES}

Browne, J., Jagdev, H.S. (1997) The Extended Enterprise: A Context for Product Development and Production. In: ICIMS - NOE (Edt.): State-Of-The-Art Surveys (SOTAS), Patras, Greece 1997

Kuhlmann, T. (1994) Konzeption und Entwicklung eines Systems zur Koordinierung der Produktion komlexer Unikate, Dissertation, University of Bremen, 1994

Kuhlmann, T., Marciniak, Z., Massow, C. (1994) Integrated Coordination Modules for the Shipbuilding Industry; in: J. Brodda; K. Johansson (Editors): $8^{\text {th }}$ International Conference on Computer Applications in Shipbuilding (Volume 2); Malmö, Sweden 1994 